\title{
Almanac 2011: Stable Coronary Artery Disease. The National Society Journals Present Selected Research That Has Driven Recent Advances in Clinical Cardiology
}

\author{
Robert A. Henderson'1, Adam D. Timmis² \\ Trent Cardiac Centre, Nottingham University Hospitals, Nottingham, United Kingdom ${ }^{1}$ \\ Barts and the London School of Medicine and Dentistry London Chest Hospital, London, United Kingdom ${ }^{2}$
}

EDITORIAL

\section{STABLE ANGINA PECTORIS}

\subsection{Diagnostic strategies}

The widespread application of specialist clinics for early evaluation of patients with chest pain has focused attention on the effectiveness of diagnostic testing. In a study of nearly 400000 patients with suspected coronary artery disease, the diagnostic yield of cardiac catheterisation was only $37.6 \%$, leading to calls for better strategies for risk stratification. 1 As pointed out in correspondence, the low yield was probably due to verification bias, itself a consequence of basing referral decisions in low-risk populations on noninvasive tests such as exercise ECG. ${ }^{2}$ Similar considerations prompted the NICE guideline group to recommend a more selective approach to non-invasive testing based on a careful clinical assessment of disease probability in patients pre-

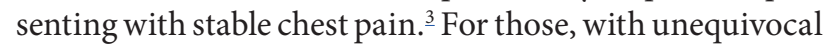
histories at the extremes of diagnostic probability $(<10 \%$ or $>90 \%$ ) no diagnostic tests were considered necessary, while for patients with a high probability of disease (60-90\%) invasive angiography without prior ischaemia testing was recommended. The NICE call for CT calcium scoring in patients with a low (10-30\%) probability of disease generated greatest concern, particularly after a report that $19 \%$ of patients without coronary calcification-who would have been ruled out for angina in the NICE algorithm - had obstructive ( $>50 \%$ stenosis) disease. ${ }^{4}$ However, the population referred for angiography in this study had a high pre-test probability of disease and in lower-risk populations CT calcium scoring retains a high diagnostic sensitivity. -5 NICE recommendations were driven largely by cost-effectiveness analysis but whether they will improve the diagnostic yield of cardiac catheterisation remains to be seen.

\subsection{Circulating biomarkers in stable angina}

The clinical role of circulating biomarkers for diagnosis of obstructive coronary artery disease in patients with *as previously published in Heart journal suspected angina has yet to be defined. In one study, blood samples for the N-terminal fragment of the prohormone brain natriuretic peptide (NT-proBNP) and various inflammatory markers were obtained in 243 patients before myocardial perfusion imaging. Only NT-proBNP proved significantly diagnostic, a cut-off concentration $<25 \quad \mathrm{ng} / \mathrm{l}$ predicting a normal perfusion scan with a negative predictive value $>95 \% .{ }^{-}$Similarly, in an angiographic study of 848 men and women with clinically suspected coronary artery disease, NT-proBNP performed better than high-sensitivity $\mathrm{C}$-reactive protein (hsCRP) and $\gamma$-glutamyltransferase, showing significant association with three-vessel coronary artery disease, but it did not add to the predictive value of traditional cardiovascular risk factors. The authors were forced to conclude that it was of limited incremental value as a diagnostic tool. $\underline{7}$ The prognostic application of circulating biomarkers in stable coronary artery disease has also been disappointing. In a meta-analysis of 83 prospective studies reporting the association of CRP with death and non-fatal cardiovascular events, the authors found that the quality of the studies was so poor (only two reported a measure of discrimination), with evidence of reporting bias and publication bias, that they were unable to make clinical practice recommendations. $\stackrel{8}{ }$ Nevertheless, the data suggested that CRP measurements are unlikely to add anything to the prognostic discrimination achieved by considering blood pressure and other clinical factors in this patient group. In another study it was concluded that conventional clinical information provided an effective means of risk-stratifying patients with stable coronary disease awaiting coronary bypass surgery and that additional prognostic information from CRP, measured singly or in combination with other biomarkers, was unlikely to be cost-effective. ${ }^{9}$

\subsection{Medical treatment of angina}

The medical treatment of angina has been the subject of renewed interest, because of the availability of new treat- 
ments such as ivabradine and ranolazine, and also because of the recognition that it can compete favourably with revascularisation in many patients, both for controlling symptoms and for improving prognosis. Thus, COURAGE showed that in patients receiving optimal medical treatment (aspirin, b blocker and statin, plus ACE inhibitor as indicated), percutaneous intervention (PCI) does not improve cardiovascular outcomes and incremental benefits in quality of life disappear by 36 months. 111 More recent meta-analyses of trials that have randomised patients with stable angina to PCI or medical treatment have come to similar conclusions. ${ }^{1213}$ This has led guideline groups to recommend optimal medical treatment for the initial management of stable angina, with revascularisation reserved principally for patients whose symptoms are not satisfactorily controlled. $\underline{14}$

\subsection{Prognosis of angina}

From the early Framingham finding that angina has 'a mortality surprisingly close to that which follows the posthospital phase of myocardial infarction' 15 to the trialists' assertions that 'cardiovascular risk (is) reduced to normal levels with contemporary therapy', $\frac{16}{}$ we now appear to have gone full circle with two recent outcome studies for patients with angina. The first included 1609 adults with ischaemic heart disease who were identified in primary care and were not, therefore, prone to the selection bias that affects secondary care cohorts. ${ }^{17}$ The investigators found the hazards of all-cause and coronary death in patients with angina alone compared with patients who had had previous myocardial infarction were 0.73 (95\% CI 0.55 to 0.98 ) and 0.65 (0.44 to 0.98$)$, respectively. Although statistically significant at the $\mathrm{p}<0.05$ level these differences were not significant at the $\mathrm{p}<0.01$ level suggested as appropriate for observational research. The investigators also found that physical functioning was consistently lower among those with angina alone. In the second study, the same group examined the prognosis of 1785 patients with angina as a first manifestation of ischaemic heart disease. ${ }^{18}$ Within 5 years, $116(6.5 \%)$ had an acute myocardial infarction, and 175 (9.8\%) died. Male sex and each year of increasing age were both associated with increased HRs for acute myocardial infarction (2.01 (1.35 to 2.97) and 1.04 (1.02 to 1.06), respectively) and all-cause mortality (1.82 (1.33 to 2.49$)$ and 1.09 (1.07 to 1.11), respectively). An important finding was that an acute myocardial infarction after the index episode of angina greatly increased the risk of subsequent death. The authors concluded that appropriate control of risk factors and optimal use of preventive medical treatments should be aggressively pursued in patients with angina who represent a high-risk group in primary care.

\section{INTERVENTIONAL MANAGEMENT OF STABLE CORONARY ARTERY DISEASE}

\subsection{Clinical trials}

Expectations that COURAGE would lead to changes in the management of stable angina, with renewed emphasis on optimal medical treatment (OMT) as the primary strategy, ${ }^{19}$ have yet to be fulfilled, raising questions about how well informed patients are about the risks and benefits of PCI. $\underline{20}$ These questions have been amplified by recent studies showing that $\mathrm{PCI}$ is recommended rather than coronary artery bypass grafting (CABG) substantially more often than indicated by international guidelines, and fulfils the US societies' criteria for appropriateness in only $50.4 \%$ of cases. ${ }^{2122}$ Rates of PCI in the USA have shown no tendency to decline since the publication of COURAGE $\underline{\underline{23}}$ and a majority of patients are not being treated with OMT. In a large study of elective PCI procedures, rates of OMT were only $43.5 \%$ in the 19 months before publication of COURAGE and $44.7 \%$, in the 24 months afterwards, confirming that COURAGE has not yet had a palpable effect on interventional practice. $\underline{24}$

Notable among recent reports from other PCI trials are the 10-year follow-up data from MASS II and the results of the STICH trial. MASS II randomised 611 patients with angina, multivessel coronary artery disease and preserved left ventricular (LV) function to initial strategies of medical treatment or PCI or CABG. ${ }^{25}$ The study was underpowered for the primary end point of total mortality, Q-wave myocardial infarction, or refractory angina needing revascularisation, which occurred less frequently in the CABG group than in the PCI and medical treatment groups (33\%, 42\% and 59\%, respectively). MASS II excluded patients with significant left main stem disease, and total mortality was similar in all three groups. Nevertheless, the findings bear comparison with those reported in the early randomised trials of CABG versus medical treatment ${ }^{\frac{26}{6}}$ where patients with multivessel disease who were randomised to CABG survived longer than those randomised to medical treatment.

STICH also has raised some doubt about the contemporary validity of those early randomised trials. In STICH 1212 patients with multivessel disease and severe impairment of left ventricular function (ejection fraction $<35 \%$ ) were randomised to coronary artery bypass surgery or medical treatment, to test whether surgical revascularisation would improve survival in this high-risk group with ischaemic left ventricular dysfunction. ${ }^{27}$ After nearly 5-years' follow-up all-cause mortality (the primary end point) was similar between the groups, both in the main trial cohort and in a subgroup with demonstrable myocardial viability. ${ }^{28}$ STICH confirms earlier reports ${ }^{29}$ that the benefits of revascularisation in patients with ischaemic cardiomyopathy may have been exaggerated, even in patients with demonstrable viability. As the editorialist commented, contemporary medical treatment should not be underestimated in the management of severe coronary artery disease. $\underline{\underline{30}}$

Meanwhile, further trials of PCI versus CABG in selected groups with left main stem disease have been consistent in favouring CABG, based almost exclusively on lower rates of repeat revascularisation compared with PCI. $\frac{31-33}{}$ None of these trials showed significant mortality differences between the two revascularisation strategies, making PCI an option for those patients unwilling to undergo surgery and prepared to accept further interventional procedures as necessary. The SYNTAX trial has already identified PCI as a reasonable strategy for symptomatic 
multivessel disease, particularly if the SYNTAX score is low $(\leq 22)$ when cardiovascular end points at 3 years are comparable to those for CABG, and this is reinforced by comparable quality-of-life outcomes. ${ }^{34-36}$ More recently, a prespecified subgroup analysis of the ARTS-II registry has reported comparable outcomes for patients with multivessel disease involving the proximal left anterior descending coronary artery treated with either sirolimus-eluting stents (SES) or CABG. ${ }^{37}$ These comparisons of PCI versus CABG in high-risk disease, and medical treatment versus $C A B G$ in ischaemic cardiomyopathy begin to erode confidence in the long-held view that surgery is the most appropriate treatment option in such patients.

\section{PROCEDURAL FACTORS}

\subsection{Radial versus femoral access}

Debate about the merits of radial versus femoral access for interventional procedures has not been resolved by RIVAL, the first comparative study powered for cardiovascular outcomes. ${ }^{38}$ Among 7021 patients with acute coronary syndrome undergoing cardiac catheterisation with a view to intervention, the primary outcome (a composite of death, myocardial infarction, stroke or non-CABG-related bleeding at 30 days) occurred in similar proportions of radial $(3.7 \%)$ and femoral $(4.0 \%)$ access groups. The marginal difference in favour of radial access was driven by a trend towards lower bleeding rates at 30 days $(0.7 \%$ vs $0.9 \%$ ), associated with significantly lower rates of access site complications, including large haematomas and pseudoaneurysms. Smaller studies ${ }^{39}$ have reported less bleeding with radial access which, coupled with earlier mobilisation, has encouraged its adoption in many European centres. Femoral access, however, is still preferred by many operators because access is more predictable, procedure times may be shorter and radiation exposure lower than with the radial approach..$^{40}$ Ultimately, it seems, institutional experience is a major determinant of procedural success, high-volume radial centres in RIVAL recording the lowest hazard of the primary outcome.

\subsection{Pressure wire}

Pressure wire measurement of fractional flow reserve (FFR) is now widely used by interventionists for per-procedural assessment of the functional significance of coronary stenoses. In the FAME study 1005 patients with multivessel coronary artery disease undergoing drug-eluting stent (DES) implantation were randomised to procedures guided by angiography alone or by angiography plus FFR measurement, values $<0.80$ providing indication for stenting. ${ }^{42}$ In the FFR group, the number of stents per patient $(1.9 \pm 1.3$ vs $2.7 \pm 1.2$ ) and the primary end point of death, non-fatal myocardial infarction or target vessel revascularisation at 1 year (13.2\% vs $18.3 \%$ ) were both significantly lower than for the angiography group. Benefits were largely sustained at 2 years ${ }^{43}$ and evidence of cost-effectiveness ${ }^{\underline{44}}$ completes the case in favour of FFR-guided PCI in multivessel procedures.

\subsection{Bifurcation $\mathrm{PCI}$}

Debate surrounding bifurcation PCI has been largely resolved by studies showing that simple stenting of the main branch-with 'provisional' stenting of the side branch only if flow becomes compromised-is better than strategies that involve complex stenting of both limbs of the bifurcation. A recent meta-analysis of randomised trials has confirmed superiority of the simple stenting strategy which yields better results for in-hospital and late myocardial infarction and similar rates of restenosis and target vessel revascularisation compared with the complex strategy. $\underline{45}$ Further refinement of the simple stenting strategy has now been tested by randomising 477 patients either to final kissing balloon inflation or to no-final kissing balloon inflation. ${ }^{46}$ Final kissing balloon inflation was associated with a significantly lower rate of angiographic side branch restenosis ( $8 \%$ vs 15\%) at 6 months compared with no-final kissing balloon inflation, although rates of the primary end point-cardiac death, myocardial infarction, stent thrombosis, or targetlesion revascularisation-were similar (2.1\% vs $2.5 \%)$. The data, therefore, do not provide a compelling argument for final kissing balloon inflation after simple birfurcation stenting, although the strategy does seem to provide some protection against side branch restenosis.

\subsection{LV support devices}

Intra-aortic balloon pump support in high-risk PCI is widely recommended, but a recent randomised trial in 301 patients with severe LV dysfunction (ejection fraction $\leq 30 \%$ ) and advanced coronary artery disease found no evidence of benefit. ${ }^{47}$ Rates of in-hospital major adverse cardiac events were similar with $(15.2 \%)$ or without $(16.0 \%)$ the intra-aortic balloon pump, arguing against its elective use in this group of patients. Alternative methods of circulatory support during PCI are now being investigated and registry data for the Impella 2.5 percutaneous LV assist device confirm that it can be safely positioned across the aortic valve from the femoral approach and supply flow rates of up to $2.5 \mathrm{l} / \mathrm{min}$ during interventional procedures. ${ }^{48}$ These promising data distinguish the Impella from most other LV assist devices, which require surgical deployment and have no role in the catheter laboratory. $\underline{49}^{-}$

\section{COMPLICATIONS}

\subsection{Acute kidney injury}

Contrast-induced acute kidney injury (AKI) is a wellrecognised complication of angiographic procedures, and a recent Canadian study shows that it has important association with adverse long-term outcomes. $\underline{50}$ Among 14782 adults undergoing cardiac catheterisation, the adjusted risk of death during a median 19.7 months' follow-up increased progressively with the post-procedural severity of AKIpatients with stage 2 or 3 AKI during the first 7 days after catheterisation having nearly four times the hazard of death compared with patients with no AKI. Risks of subsequent hospitalisations for heart failure also increased. Interestingly, AKI has been reported less commonly with catheterisation using the radial approach compared with the femoral approach. $\underline{\text { }}$ Pre-hydration may be protective in high-risk individuals, particularly people with diabetes, but no other specific treatments have shown unequivocal benefit.

\subsection{Bleeding}

Peri-procedural bleeding, associated with adverse outcomes after PCI, has declined notably in recent years. $\underline{52}$ Radial access has probably contributed (see above) but other bleeding avoidance strategies have been emphasised 
in a study of 1522935 patients entered in the National Cardiovascular Data Registry CathPCI Registry. $\underline{53}$ The study showed that vascular closure devices and bivalirudin therapy together were associated with a reduction of bleeding events from $2.8 \%$ to $0.9 \%$, yet these strategies were used least often in patients with a high pre-procedural risk of bleeding assessed with the National Cardiovascular Data Registry bleeding risk model. $\stackrel{54}{ }$ Based on these findings it seems clear that there remains considerable scope for improving the safety of PCI by pre-procedural identification of patients with most to gain from individualised bleeding avoidance strategies.

Myocardial injury

Myocardial injury during PCI is common and a recent meta-analysis of 15 studies embracing 7578 patients found troponin elevation in $28.7 \%$ of procedures. $\frac{55}{}$ Any level of raised troponin was associated with an increased risk of cardiovascular events and for those with myocardial infarction according to the universal definition ${ }^{56}$ the OR for major adverse cardiac events at 18 months was 2.25 (1.26 to 4.00). Direct evidence of peri-procedural myocardial injury has now been made available from cardiovascular magnetic resonance imaging, which documented new myocardial hyperenhancement (median mass $5.0 \mathrm{~g}$ ) in $32 \%$ of 152 patients undergoing PCI. After adjustment for age and sex, these patients had a 3.1 -fold ( $95 \%$ CI 1.4 to $6.8 ; \mathrm{p}=0.004$ ) higher risk of adverse outcome than patients without new hyperenhancement. ${ }^{57}$ These data have enhanced interest in pharmacological and mechanical interventions directed at protecting the myocardium during elective PCI. High-dose statins show promise in this regard, and in one study of 668 statin-naïve patients, peri-procedural myocardial infarction (defined as a CK-MB elevation $>3^{\prime}$ upper limit of normal) occurred in $9.5 \%$ of those randomised to a single loading dose of atorvastatin $80 \mathrm{mg}$, compared with $15.8 \%$ in the control group. $\frac{58}{}$ Most patients should already be taking statins before elective PCI but for those who are not, these data indicate that pre-procedural loading together with aspirin and clopidogrel is a potential means of enhancing patient safety. Also promising is remote ischaemic preconditioning, which in a recent randomised trial of 242 patients undergoing elective PCI was associated with reduced troponin I release at $24 \mathrm{~h}$ compared with controls ( 0.06 vs $0.16 \mathrm{ng} / \mathrm{ml} ; \mathrm{p}=0.040)$. $\underline{\text { ⒐ }}$ The major adverse cardiac and cerebral event rate at 6 months was also lower in the remote ischaemic preconditioning group (4 vs 13 events; $\mathrm{p}=0.018)$. However, this was a small unblinded trial and further research is needed before this inexpensive means of myocardial protection can be recommended in routine clinical practice.

\section{PCI IN SPECIAL GROUPS}

\subsection{Prior radiotherapy}

Thoracic radiotherapy in women with breast cancer increases the long-term risk of cardiovascular death, ${ }^{60}$ possibly by induction of a sustained inflammatory response in irradiated arteries. ${ }^{61}$ It is also associated with adverse outcomes for coronary stenting, with a HR for all-cause death after 6 years of 4.2 (95\% CI 1.8 to 9.5) compared with people who have not undergone radiotherapy. .2

\subsection{Diabetes}

$\mathrm{CABG}$ has long been the preferred revascularisation strategy in patients with diabetes and multivessel disease, and the publication of BARI-2D and CARDia has done little to challenge this orthodoxy. In BARI-2D, 2368 patients with type 2 diabetes ( $31 \%$ with three-vessel disease) were stratified as being appropriate for either PCI or CABG and then randomised to contemporary medical treatment or revascularisation. $\frac{63}{}$ After follow-up for an average of 5.3 years, rates of all-cause mortality (the primary end point) were similar for the medical and revascularisation groups, but in the CABG stratum, patients assigned to revascularisation had lower cardiovascular event rates (death, myocardial infarction (MI) or stroke) than patients assigned to medical treatment. However, the patients in BARI-2D randomised to revascularisation obtained greater symptomatic benefit than the medically treated group. $\underline{\underline{64}}$

In CARDia, 510 patients with diabetes, $93 \%$ of whom had multivessel disease, were randomised to PCI or CABG. ${ }^{65}$ The composite rate of all-cause mortality, non-fatal MI, and non-fatal stroke at 1 year was $13.0 \%$ for PCI and $10.5 \%$ for CABG; this difference was not statistically significant but the study was powered and non-inferiority for PCI compared with CABG was not confirmed. It is the BARI2D findings, therefore, that generated greater interest by showing that contemporary medical treatment of diabetic patients with complex coronary artery disease compares favourably with revascularisation.

\subsection{Outcomes for $\mathrm{PCI}$}

Outcomes for PCI (and for CABG) continue to improve. ${ }^{66}$ Pre-procedural risk factors for adverse outcomes are well defined and include impaired LV function, complex lesion morphology, emergency procedures and diabetes. To this list may now be added the EuroSCORE, which showed excellent discrimination for predicting hospital mortality (area under the receiver operating characteristic curve 0.91 ( $95 \%$ CI 0.86 to 0.97 )) in 1173 PCI patients, with the odds of death increasing as the score rose. ${ }^{67}$ The EuroSCORE is already validated and widely used to predict surgical risk and the authors suggest that it is therefore well placed to help cardiologists and cardiac surgeons individualise the risk profile of patients in order to better select the appropriate revascularisation strategy. External validation of the EuroSCORE in other PCI cohorts is now needed before its clinical application can be confidently recommended. Meanwhile the SYNTAX score, based on specific anatomical characteristics of the coronary angiogram, remains the best validated means of anticipating the risks of PCI and CABG, although its value for predicting 12-month outcomes is confined to PCI. $\underline{68}$

\subsection{Second-generation DES}

DES have produced important reductions in rates of restenosis compared with bare metal stents (BMS), albeit at increased risk of late stent thrombosis. ${ }^{69}$ This has provided impetus for the design of more effective 'second-generation' DES that have been the subject of investigation in four recent trials, all of which were powered for clinical events with a primary composite end point of cardiac death, myocardial infarction, or target-vessel revascularisation. The largest of these, SPIRIT IV, randomised 3687 patients in a 2:1 ratio to 
receive second-generation everolimus-eluting stents (EES) or first-generation paclitaxel-eluting stents (PES). $\underline{70}$ The study confirmed superiority of EES over PES for the composite clinical end point (4.2\% vs $6.8 \%)$, and also for stent thrombosis $(0.2 \%$ vs $0.8 \%)$. The single-centre COMPARE trial compared second-generation EES with second-generation PES in 1800 patients and again showed superiority of the EES, which at 12 months was associated with a $6 \%$ incidence of the primary end point compared with $9 \%$ in the PES group. ${ }^{\underline{11}}$ The second-generation zotarolimus-eluting stent (ZES) has been evaluated against sirolimus-eluting (SORT OUT III, $\mathrm{n}=2332$ ) and EES (Resolute All Comers Trial, $\mathrm{n}=2292$ ). In SORT OUT III, ZES proved inferior to SES, with primary end point rates of $6 \%$ versus $3 \%$, a difference sustained at 18 months. $\stackrel{72}{ }$ In Resolute All Comers the composite clinical end point at 1 year occurred in almost identical (8.2\% and $8.3 \%$ ) proportions of ZES and EES groups, but the ZES group showed a tendency for more frequent stent thrombosis $(2.3 \%$ vs $1.5 \%)$ and greater in-stent late lumen loss $(0.27 \mathrm{~mm}$ vs $0.19 \mathrm{~mm})$. These observations raise further concerns about ZES that will not be resolved until the 5-year follow-up data become available. ${ }^{73}$ Long-term results of ZES have been favourable in registries, ${ }^{74}$ but the results of these four randomised trials have ensured that second-generation EES are now the first choice for most interventionists.

Moving beyond the second generation of DES, polymerfree and biodegradable polymer DES are now entering the clinical arena. A randomised comparison of rapamycin delivery using these novel platforms versus conventional (permanent) polymer coated sirolimus-eluting stents, showed comparable safety and comparable efficacy for prevention of clinical restenosis during the 2-year followup. However, angiographic surveillance confirmed more sustained neointimal suppression with the polymer-free rapamycin-eluting stent than with the other platforms..$^{75}$ Everolimus delivery by a bioabsorbable stent in 30 patients also produced impressive 2-year outcomes with no cardiac deaths, ischaemia-driven target lesion revascularisations, or stent thromboses recorded. $\frac{76}{}$ Interestingly, vasomotion was restored in the stented segment after bioabsorption. These results will doubtless ensure continuing interest in the development of polymer-free DES.

\subsection{Bare metal stents}

The advantages offered by DES in management of coronary artery disease have seen continuing indications for BMS diminish almost to the point of extinction. The superiority of DES compared with BMS for primary PCI is driven by significantly lower rates of target lesion revascularisation, and recent data show that the benefit is sustained after 3 years (9.4\% vs $15.1 \%$ ) with no significant differences in the rates of death, reinfarction, or stent thrombosis. ${ }^{77}$ Current recommendations are for the preferential use of DES in ST elevation myocardial infarction, particularly in patients with high-risk features for restenosis such as long lesions, small vessels, or diabetes. $\stackrel{78}{ }$ The BASKET-PROVE study now also challenges the notion that BMS have residual indications in large coronary arteries. ${ }^{79}$ These investigators randomised 2314 patients requiring 3-4 mm diameter coronary stents to receive first-generation SES, second- generation EES, or cobalt-chromium BMS. After 2 years cardiovascular event rates and rates of stent thrombosis were comparable between the three groups, but the rates of clinically driven target lesion revascularisation [Marion, the author had TVR here but I think it should have been TLR as expanded] were only $4.3 \%$ with SES and $3.7 \%$ with EES compared with $10.3 \%$ with BMS. Although cost-effectiveness was not reported, these findings confirm that the benefits of DES for safety and protection against restenosis in small coronary arteries extend to procedures undertaken in larger vessels.

\subsection{Paclitaxel-coated balloon}

PCI in very small vessels $(<3 \quad \mathrm{~mm})$ remains a challenge. Use of DES has improved safety and longer-term outcomes relative to $\mathrm{BMS}, \underline{80}$ and in a randomised trial proved better than the newly available paclitaxel-coated balloon for restenosis after 6 months. $\frac{81}{}$ Nevertheless, a potentially important coronary application of the paclitaxel-coated balloon for treatment of in-stent restenosis has now been identified. A recent randomised trial in 131 patients with bare metal in-stent restenosis reported 6-month binary restenosis rates of only $7 \%$ for the drug-coated balloon compared with $20 \%$ for a paclitaxel-eluting stent. $\stackrel{82}{\text { How- }}$ ever, longer-term data will be needed. A recent registry study reported that SES used for treatment of bare metal in-stent restenosis exhibited sustained efficacy at 4 years with a target lesion revascularisation rate of only $11.1 \% . \underline{83}$

\section{ANTIPLATELET THERAPY 6.1. Stent thrombosis}

Dual antiplatelet therapy with aspirin and clopidogrel (DAPT) is considered an essential adjunct to PCI to protect against stent thrombosis. Guidelines recommend that DAPT is continued for 12 months in patients who have received a DES to allow for complete endothelialisation of the struts, whereupon treatment can continue with aspirin alone. However, very late stent thrombosis remains a real concern and has received attention in a number of recent studies either by evaluating the potential benefits of prolonging DAPT beyond 12 months or by up-titrating antiplatelet therapy against the results of platelet function tests. The impact of prolonged DAPT beyond 12 months has been evaluated in a registry study, which found no additional protection against death or MI compared with

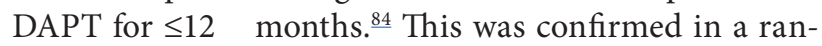
domised trial of continuing aspirin and clopidogrel versus monotherapy with aspirin in 2701 patients who had already received DAPT for 12 months after PCI. $\frac{85}{}$ At 2 -years' follow-up, rates of MI and death were similar in the two groups (1.8\% vs $1.2 \%$ ), providing support for the guideline recommendation to continue DAPT for 12 months after PCI with DES. However, the importance of strict adherence to DAPT in the first 12 months is emphasised by the finding in another recent study that patients who delayed filling their prescription for clopidogrel after hospital discharge had almost twice the risk of MI or death compared with those who filled their prescription on the day of discharge, even though the median delay was only 3 days. $\underline{86}$ 


\subsection{High residual platelet reactivity}

An alternative approach for protecting against stent thrombosis is to target more aggressive treatment at patients with high residual platelet reactivity after clopidogrel loading. Such patients appear to be at significantly increased risk of adverse events, and in a recent study of 215 patients undergoing unprotected left main stem PCI the risk of cardiac death at 1 year was more than doubled in those with high residual platelet activity. ${ }^{87}$ The GRAVITAS investigators have now reported their randomised comparison of standard dose $(75 \mathrm{mg})$ versus high-dose $(150 \mathrm{mg})$ clopidogrel after drug-eluting stenting in 2214 patients with high on-treatment platelet reactivity. $\frac{88}{\text { Although high-dose }}$ clopidogrel was effective in reducing platelet reactivity, cardiovascular event rates (death, myocardial infarction, stent thrombosis) after 6 months were identical at 2.3\% in both groups. The failure of aggressive antiplatelet treatment to reduce event rates in patients with high residual platelet reactivity was, perhaps, surprising but will not be the last word on this subject, as other such studies are in progress. Meanwhile, calls for platelet reactivity monitoring in patients receiving clopidogrel seem premature. $\underline{\underline{ }}$.

A potential mechanism of high residual platelet reactivity in some patients treated with clopidogrel relates to conversion of the prodrug to an active metabolite by the hepatic cytochrome P-450 system. Conversion is genetically determined and is reduced in carriers of common loss-of-function CYP alleles, who show decreased platelet inhibition and a 1.53 to 3.69 increased risk of cardiovascular events compared with non-carriers. ${ }^{90-92}$ This led to calls for higher clopidogrel dosing in carriers of the loss-of-function alleles but this policy has now been questioned by a study that stratified patients enrolled in two large randomised trials of clopidogrel therapy by genotype status. ${ }^{93}$ In neither trial did loss-of-function carrier status affect the primary composite efficacy outcomes, or safety outcomes with respect to bleeding. The authors concluded that carriers of loss-of-function CYP alleles should receive clopidogrel at currently recommended doses in acute coronary syndromes, although for atrial fibrillation the conclusion was qualified by a need for larger studies. Meanwhile, genotyping of patients with acute coronary syndromes enrolled in a head-to-head comparison of clopidogrel with ticagrelor (PLATO) reported that the hazard of the primary endpoint was lower for patients randomised to ticagrelor compared with clopidogrel but RR reduction was unaffected by CYP or ABCB1 (coding for a protein influencing clopidogrel absorption) genotype. ${ }^{94}$ On present evidence, therefore, genetic testing does not appear to be helpful in determining clopidogrel's effectiveness in comparison with placebo or ticagrelor and is unlikely to provide a useful basis for determining dosing strategies.

Drug interaction

Another potential mechanism of high residual platelet reactivity in some patients receiving platelet inhibitors is an interaction with some proton pump inhibitors (PPIs), which may reduce clopidogrel's conversion to its active metabolite by interfering with the hepatic cytochrome P-450 system and may also reduce the platelet response to aspirin. ${ }^{95}$ However, in a large cohort study event rates among patients dis- charged on PPIs were increased independently of whether or not they were also discharged on clopidogrel, indicating that drug interaction was not the responsible mechanism. ${ }^{96}$ Moreover, the COGENT trial of 3873 patients receiving DAPT and randomised to omeprazole or placebo was reassuring in showing no difference in the primary cardiovascular end point, a composite of death from cardiovascular causes, non-fatal myocardial infarction, revascularisation, or stroke. ${ }^{97}$ COGENT found that patients randomised to omeprazole had a significantly lower rate of gastrointestinal bleeding and, given the gastro-protective effects of PPIs in patients on low-dose aspirin, recently confirmed in the OBERON trial, 98 the benefits seem to outweigh any potential risk related to clopidogrel interaction. Other drugs that have come under recent scrutiny include calcium channel blockers which, like PPIs, are metabolised by the hepatic cytochrome P-450 system and have the potential therefore to interact with clopidogrel. Observational data in patients taking clopidogrel have shown that high residual platelet reactivity is more common in those co-prescribed calcium channel blockers than in those who are not, ${ }^{99}$ and an earlier observational study reported that this may be associated with a higher cardiovascular event rate 2 years after PCI. ${ }^{100}$ Interpretation of these studies needs to be cautious, however, and more prospective data are needed, ideally in the form of randomised trials.

\section{CORONARY ARTERY BYPASS SURGERY IN STABLE CORONARY DISEASE}

Among key technical innovations of the last 15 years has been off-pump CABG but its potential benefits for myocardial and cerebral protection have had to be weighed against problems of incomplete revascularisation and reports of an increased risk of myocardial infarction and early graft attrition compared with on-pump procedures. Two randomised trials have now clarified some of these issues. The ROOBY investigators randomised 2203 patients to on-pump or off-pump CABG and found no significant difference in rates of the 30-day composite outcome $7.0 \%$ vs $5.6 \%$, respectively for death, reoperation, new mechanical support, cardiac arrest, coma, stroke, or renal failure). .101 After 1 year the same composite was higher for off-pump than for on-pump CABG (9.9\% vs 7.4\%, $\mathrm{p}=0.04)$ and graft patency was lower $(82.6 \%$ vs $87.8 \%, \mathrm{p}<0.01)$ in the 1371 patients who had follow-up angiography. Meanwhile, a careful assessment of 12-month cognitive outcomes found no difference between the groups, although the rate of impairment by either procedure was reassuringly low. ${ }^{102}$

Shortly after the ROOBY report, the 'Best Bypass Surgery' trialists published their results in a higher risk group (EuroSCORE $\geq 5$, three-vessel disease) of 341 patients randomised to on-pump or off-pump CABG. ${ }^{103}$ Again, the composite primary outcome (all-cause mortality, acute myocardial infarction, cardiac arrest with successful resuscitation, low cardiac output syndrome/cardiogenic shock, stroke, and coronary reintervention) was similar for the onpump and off-pump groups ( $15 \%$ and $17 \%$; $=0.48$ ) and after 3 years all-cause mortality was significantly increased 
in the off-pump group (24\% vs $15 \%$; HR $1.66,95 \%$ CI 1.02 to $2.73 ; \mathrm{p}=0.04) .004$ These trials have not provided evidence of clinical superiority for off-pump CABG, although it is premature to consider abandoning the procedure. Conventional cardiopulmonary bypass has important deleterious effects that include platelet and neutrophil activation, consumption of coagulation factors, complement generation and the release of proinflammatory mediators with generation of a systemic inflammatory response. If off-pump surgery cannot deliver better clinical outcomes it may be prudent to take heed of the editorialist and consider 'betterbypass' in the form of a miniaturised bypass system. ${ }^{105}$ This was the subject of a recent meta-analysis which found that miniaturised cardiopulmonary bypass in comparison with conventional cardiopulmonary bypass was associated with a somewhat lower rate of death (1.1\% vs $2.2 \%$, OR $0.58,95 \%$ CI 0.23 to $1.47, \mathrm{p}=0.25)$ and stroke $(0.2 \%$ vs $2.0 \%$, OR 0.25 , 95\% CI 0.06 to $1.00, \mathrm{p}=0.05)$ in the immediate postoperative period. ${ }^{106}$ Now needed are larger trials to further evaluate miniaturised cardiopulmonary bypass.

\section{REFERENCES}

1. Patel MR, Peterson ED, Dai D, et al. Low diagnostic yield of elective coronary angiography. N Engl J Med2010;362:886-95.

2. Diamond GA, Kaul S. Low diagnostic yield of elective coronary angiography. N Engl J Med_2010;363:93; author reply 94-5.

3. Skinner JS, Smeeth $\mathrm{L}_{2}$ Kendall $\mathrm{JM}_{2}$ et al; Chest Pain Guideline Development Group. NICE guidance. Chest pain of recent onset: assessment and diagnosis of recent onset chest pain or discomfort of suspected cardiac origin. Heart 2010;96:974-8.

4. Gottlieb I, Miller JM, Arbab-Zadeh A, et al. The absence of coronary calcification does not exclude obstructive coronary artery disease or the need for revascularization in patients referred for conventional coronary angiography. J Am Coll Cardiol_2010;55:627_34.

5. Nieman $\mathrm{K}$, Galema T, Weustink A, et al. Computed tomography versus exercise electrocardiography in patients with stable chest complaints: real-world experiences from a fasttrack chest pain clinic. Heart_2009;95:1669_75.

6. Rathcke CN, Kjoller E, Fogh-Andersen N, et al. NT-proBNP and circulating inflammation markers in prediction of a normal myocardial scintigraphy in patients with symptoms of coronary artery disease. PLoS One 2010;5:e14196.

7. Peer $\mathrm{A}_{2}$ Falkensammer $\mathrm{G}, \mathrm{Alber} \mathrm{H}_{2}$ et al_Limited utilities of $\mathrm{N}$-terminal pro B-type natriuretic peptide and other newer risk markers compared with traditional risk factors for prediction of significant angiographic lesions in stable coronary artery disease. Heart 2009;95:297_303.

8. Hemingway $\mathrm{H}_{2}$ Philipson $\mathrm{P}, \mathrm{Chen} \mathrm{R}$, et al. Evaluating the quality of research into a single prognostic biomarker: a systematic review and meta-analysis of 83 studies of $\mathrm{C}$-reactive protein in stable coronary artery disease. PLoS Med 2010;7:e1000286.

9. Hemingway $\mathrm{H}_{2}$ Henriksson $\mathrm{M}_{2}$ Chen $\mathrm{R}_{2}$ et al. The effectiveness and cost-effectiveness of biomarkers for the prioritisation of patients awaiting coronary revascularisation: a systematic review and decision model. Health Technol Assess 2010;14:1_151, iii-iv.

10. Boden WE, O’Rourke RA, Teo KK, et al. Optimal medical therapy with or without PCI for stable coronary disease. $\mathrm{N}$
Engl J Med_2007;356:1503-16.

11. Weintraub WS, Spertus JA, Kolm P, et al; COURAGE Trial Research Group. Effect of PCI on quality of life in patients with stable coronary disease. N Engl J Med_2008;359:677_87.

12. Thomas $S_{2}$ Gokhale R, Devereaux PJ, et al. Meta-analysis of randomized controlled trialscomparing percutaneous coronary intervention with medical therapy in patients with stable angina. J Am Coll Cardiol_2011;57:E961.

13. Wijeysundera $\mathrm{HC}_{2}$ Nallamothu $\mathrm{BK}$, Krumholz $\mathrm{HM}_{2}$ et al. Meta-analysis: effects of percutaneous coronary intervention versus medical therapy on angina relief. Ann Intern Med 2010;152:370_9.

14. National Clinical Guideline Centre: Stable Angina. http:// www.nice.org.uk (in production).

15. Kannel WB, Feinleib M.Natural history of angina pectoris in the Framingham study. Prognosis and survival.Am J Cardiol 1972;29:154-63.

16. Pitt B.ACE inhibitors for patients with vascular disease without left ventricular dysfunction-may they rest in PEACE? N Engl J Med 2004;351:2115-17.

17. Buckley $B_{2}$ Murphy AW. Do patients with angina alone have a more benign prognosis than patients with a history of acute myocardial infarction, revascularisation or both? Findings from a community cohort study. Heart 2009;95:461-7.

18. Buckley BS, Simpson CR, McLernon DJ, et al. Five year prognosis in patients with angina identified in primary care: incident cohort study._BMJ_2009;339;b3058.

19. Fox KA. COURAGE to change practice? Revascularisation in patients with stable coronary artery disease. Heart 2009;95:689_92.

20. Rothberg $\mathrm{MB}_{2}$ Sivalingam $\mathrm{SK}_{2}$ Ashraf J, et al. Patients' and cardiologists' perceptions of the benefits of percutaneous coronary intervention for stable coronary disease. Ann Intern Med_2010;153:307_13.

21. Hannan EL, Racz MJ, Gold J, et al; American College of Cardiology; American Heart Association. Adherence of catheterization laboratory cardiologists to American College of Cardiology/American Heart Association guidelines for percutaneous coronary interventions and coronary artery bypass graft surgery: What happens in actual practice?_Circulation 2010;121:267-75.

22. Chan PS, Patel MR, Klein LW, et al.Appropriateness of percutaneous coronary intervention.JAMA_2011;306:53-61.

23. Epstein AJ, Polsky D, Yang F, et al. Coronary revascularization trends in the United States, 2001-2008.JAMA 2011;305:1769-76.

24. Borden WB, Redberg RF, Mushlin AI, et al. Patterns and intensity of medical therapy in patients undergoing percutaneous coronary intervention. JAMA_2011;305:1882_9.

25. Hueb W, Lopes N, Gersh BJ, et al. Ten-year follow-up survival of the Medicine, Angioplasty, or Surgery Study (MASS II). A randomized controlled clinical trial of 3 therapeutic strategies for multivessel coronary artery disease. Circulation_2010;122:943-5.

26. Yusuf $S_{2}$ Zucker $D_{2}$ Peduzzi $P_{2}$ et al. Effect of coronary artery bypass graft surgery on survival: overview of 10-year results from randomised trials by the Coronary Artery Bypass Graft Surgery Trialists Collaboration._Lancet_1994;344:563_70.

27. Velazquez EJ, Lee KL, Deja MA, et al; STICH Investigators. Coronary-artery bypass surgery in patients with left ventricu- 
lar dysfunction._N Engl J Med_2011;364:1607_16.

28. Bonow RO, Maurer G, Lee KL, et al; STICH Trial Investigators. Myocardial viability and survival in ischemic left ventricular dysfunction._N Engl J Med_2011;364:1617_25.

29. Rizzello V, Poldermans D, Biagini E, et al. Prognosis of patients with ischaemic cardiomyopathy after coronary revascularisation: relation to viability and improvement in left ventricular ejection fraction. Heart 2009;95:1273-7.

30. Fang JC. Underestimating medical therapy for coronary disease $1 / 4$ again. N Engl J Med_2011;364:1671_3.

31. Park SJ, Kim YH, Park DW, et al. Randomized trial of stents versus bypass surgery for left main coronary artery disease. N Engl J Med_2011;364:1718_27.

32. Morice MC, Serruys PW, Kappetein AP, et al._Outcomes in patients with de novo left main disease treated with either percutaneous coronary intervention using paclitaxel- eluting stents or coronary artery bypass graft treatment in the Synergy Between Percutaneous Coronary Intervention with TAXUS and Cardiac Surgery (SYNTAX) trial.Circulation 2010;121:2645-53.

33. Boudriot $\mathrm{E}$, Thiele $\mathrm{H}_{2}$ Walther $\mathrm{T}$, et al_Randomized comparison of percutaneous coronary intervention with sirolimus-eluting stents versus coronary artery bypass grafting in unprotected left main stem stenosis. J Am Coll Cardiol 2011:57:538_45.

34. Serruys PW, Morice MC, Kappetein AP, et al; SYNTAX Investigators. Percutaneous coronary intervention versus coronary-artery bypass grafting for severe coronary artery disease. N Engl J Med 2009;360:961-72.

35. AP Kappetein, TE Feldman, MJ Mack, et al_Comparison of coronary bypass surgery with drug-eluting stenting for the treatment of left main and/or three-vessel disease: 3-year follow-up of the SYNTAX trial.Eur Heart J. Published Online First: 22 January 2011.

36. Cohen DJ, Van Hout B, Serruys PW, et al; for the Synergy between PCI with Taxus and Cardiac Surgery (SYNTAX) Investigators.Quality of life after PCI with drug-eluting stents or coronary-artery bypass surgery. N Engl J Med 2011;364:1016_26.

37. Kukreja $\mathrm{N}_{2}$ Serruys $\mathrm{PW}$, De Bruyne $\mathrm{B}_{2}$ et al; ARTS-II Investigators. Sirolimus-eluting stents, bare metal stents or coronary artery bypass grafting for patients with multivessel disease including involvement of the proximal left anterior descending artery: analysis of the Arterial Revascularization Therapies study part 2 (ARTS-II)._Heart_2009;95:1061_6.

38. Jolly SS, Yusuf $\mathrm{S}_{2}$ Cairns $\mathrm{J}_{2}$ et al; for the RIVAL Trial Group. Radial versus femoral access for coronary angiography and intervention in patients with acute coronary syndromes (RI$\mathrm{VAL}$ ): a randomised, parallel group, multicentre trial_Lancet 2011;377:1409-20

39. Pristipino $\mathrm{C}_{2}$ Trani $\mathrm{C}_{2}$ Nazzaro $\mathrm{MS}_{2}$ et al 2 Prospective REgistry of Vascular Access in Interventions in Lazio Region Study Group. Major improvement of percutaneous cardiovascular procedure outcomes with radial artery catheterisation: results from the PREVAIL study.Heart_2009;95:476_82.

40. Brueck M, Bandorski D, Kramer W, et al. A randomized comparison of transradial versus transfemoral approach for coronary angiography and angioplasty. JACC Cardiovasc Interv_2009;2:1047-54.

41. Lo TS, Nolan J, Fountzopoulos E, et al._Radial artery anomaly and its influence on transradial coronary procedural outcome. Heart 2009;95:410-15.

42. Tonino $\mathrm{PA}_{2}$ De Bruyne $\mathrm{B}_{2}$ Pijls $\mathrm{NH}_{2}$ et al; for the FAME Study Investigators. Fractional flow reserve versus angiography for guiding percutaneous coronary intervention. $\mathrm{N}$ Engl J Med 2009;360:213-24.

43. Pijls $\mathrm{NH}_{2}$ Fearon $\mathrm{WF}_{2}$ Tonino $\mathrm{PA}_{2}$ et al $\mathrm{l}_{2}$ FAME Study Investigators. Fractional flow reserve versus angiography for guiding percutaneous coronary intervention in patients with multivessel coronary artery disease: 2-year follow-up of the FAME (Fractional Flow Reserve Versus Angiography for Multivessel Evaluation) study.J Am Coll Cardiol_2010;56:177_84.

44. Fearon $\mathrm{WF}_{2}$ Bornschein $\mathrm{B}_{2}$ Tonino $\mathrm{PA}_{2}$ et al; Fractional Flow Reserve Versus Angiography for Multivessel Evaluation (FAME) Study Investigators. Economic evaluation of fractional flow reserve guided percutaneous coronary intervention in patients with multivessel disease. Circulation 2010;122:2545_50.

45. Zhang F, Dong L, Ge J.Simple versus complex stenting strategy for coronary artery bifurcation lesions in the drugeluting stent era: a meta-analysis of randomised trials._Heart 2009; $95: 1676-81$.

46. Niemelä M, Kervinen K, Erglis A, et al; Nordic-Baltic PCI Study Group. Randomized comparison of final kissing balloon dilatation versus no final kissing balloon dilatation in patients with coronary bifurcation lesions treated with main vessel stenting: The Nordic-Baltic Bifurcation Study III_Circulation 2011;123:79-86.

47. Perera $\mathrm{D}$, Stables $\mathrm{R}$, Thomas $\mathrm{M}$, et al; BCIS-1 Investigators. Elective intra-aortic balloon counterpulsation during highrisk percutaneous coronary intervention: a randomized controlled trial. JAMA_2010;304:867-74.

48. Sjauw $\mathrm{KD}_{2}$ Konorza $\mathrm{T}_{2}$ Erbel $\mathrm{R}_{2}$ et al_Supported high-risk percutaneous coronary intervention with the Impella 2.5 device: The Europella registry. J Am Coll Cardiol_2009;54:2430-4.

49. 49Birks EJ_Left ventricular assist devices._Heart_2010;96:63= 71.

50. James MT, Ghali WA, Knudtson ML, et al; for the Alberta Provincial Project for Outcome Assessment in Coronary Heart Disease (APPROACH) Investigators._Associations between acute kidney injury and cardiovascular and renal outcomes after coronary angiography._Circulation_2011;123:409_16.

51. Vuurmans $\mathrm{T}_{2}$ Byrne J, Fretz ER, et al_Chronic kidney injury in patients after cardiac catheterisation or percutaneous coronary intervention: a comparison of radial and femoral approaches (from the British Columbia Cardiac and Renal Registries). Heart 2010;96:1538-154.

52. Roe MT, Messenger JC, Weintraub WS, et al. Treatments, trends, and outcomes of acute myocardial infarction and percutaneous coronary intervention. J Am Coll Cardiol 2010;56:254-63.

53. Marso $\mathrm{SP}_{2}$ Amin $\mathrm{AP}_{2}$ House JA, et al_.Association between use of bleeding avoidance strategies and risk of periprocedural bleeding among patients undergoing percutaneous coronary intervention.JAMA_2010;303:2156_64.

54. Mehta SK, Frutkin AD, Lindsey JB, et al; National Cardiovascular Data Registry._Bleeding in patients undergoing percutaneous coronary intervention: the development of a clinical risk algorithm from the National Cardiovascular Data Registry._Circ Cardiovasc Interv_2009;2:222_9. 
55. Testa $\mathrm{L}_{2}$ Van Gaal WJ, Biondi Zoccai GG, et al._Myocardial infarction after percutaneous coronary intervention: a metaanalysis of troponin elevation applying the new universal definition.QQJM_2009;102:369_78.

56. Hall AS, Barth JH. Universal definition of myocardial infarction. Heart_2009;95:247-9.

57. Rahimi $\mathrm{K}_{2}$ Banning $\mathrm{AP}_{2}$ Cheng $\mathrm{AS}_{2}$ et al. Prognostic value of coronary revascularisation-related myocardial injury: a cardiac magnetic resonance imaging study_.Heart 2009;95:1937_43.

58. Briguori $\mathrm{C}_{2}$ Visconti $\mathrm{G}_{2}$ Focaccio $\mathrm{A}_{2}$ et al__Novel approaches for preventing or limiting events (Naples) II trial: impact of a single high loading dose of atorvastatin on periprocedural myocardial infarction. J Am Coll Cardiol 2009;54:2157-63.

59. Hoole SP, Heck PM, Sharples L, et al. Cardiac Remote Ischemic Preconditioning in Coronary Stenting (CRISP Stent) study: a prospective, randomized control trial. Circulation 2009;119:820-7.

60. Bouillon $\mathrm{K}_{2}$ Haddy $\mathrm{N}_{2}$ Delaloge $\mathrm{S}_{2}$ et al__Long-term cardiovascular mortality after radiotherapy for breast cancer.J Am Coll Cardiol 2011;57:445-52

61. Halle $\mathrm{M}_{2}$ Gabrielsen $\mathrm{A}_{2}$ Paulsson-Berne $\mathrm{G}_{2}$ et al_Sustained inflammation due to nuclear factor-kappa $B$ activation in irradiated human arteries. J Am Coll Cardiol 2010;55:1227-36.

62. Dubois $\mathrm{CL}_{2}$ Pappas $\mathrm{C}_{2}$ Belmans $\mathrm{A}_{2}$ et al_Clinical outcome of coronary stenting after thoracic radiotherapy: a case-control study. Heart 2010;96:678-82.

63. Frye $\mathrm{RL}_{2}$ August $\mathrm{P}_{2}$ Brooks $\mathrm{MM}_{2}$ et al $\mathrm{l}_{2} \mathrm{BARI} 2 \mathrm{D}$ Study Group. $\mathrm{A}$ randomized trial of therapies for type 2 diabetes and coronary artery disease. N Engl J Med 2009;360:2503-15.

64. Dagenais $\mathrm{GR}_{2} \mathrm{Lu}_{2}$ Faxon $\mathrm{DP}_{2}$ et al; Bypass Angioplasty Revascularization Investigation 2 Diabetes (BARI 2D) Study Group. Effects of optimal medical treatment with or without coronary revascularization on angina and subsequent revascularizations in patients with type 2 diabetes mellitus and stable ischemic heart disease. Circulation 2011;123:1492-500.

65. Kapur A,Hall RJ, Malik IS, et al__Randomized comparison of percutaneous coronary intervention with coronary artery bypass grafting in diabetic patients: 1-year results of the CARDia (Coronary Artery Revascularization in Diabetes) trial_J Am Coll Cardiol_2010;55:432_40.

66. Blackledge $\mathrm{HM}$, Squire IB. Improving long-term outcomes following coronary artery bypass graft or percutaneous coronary revascularisation: results from a large, population-based cohort with first intervention 1995-2004. Heart 2009;95:304-11,

67. Romagnoli $\mathrm{E}_{2}$ Burzotta $\mathrm{F}_{2}$ Trani $\mathrm{C}_{2}$ et al._EuroSCORE as predictor of in-hospital mortality after percutaneous coronary intervention._Heart_2009;95:43-8.

68. Serruys PW, Onuma $\mathrm{Y}_{2}$ Garg S $\mathrm{S}_{2}$ et al_Assessment of the SYNTAX score in the Syntax study. EuroIntervention 2009;5:50-6.

69. Garg $S_{2}$ Serruys PW.Drug-eluting stents: a reappraisal_.Heart 2010;96:489-93.

70. Stone GW, Rizvi A, Newman W, et al; SPIRIT IV Investigators. Everolimus-eluting versus paclitaxel-eluting stents in coronary artery disease. $\mathrm{N}$ Engl J Med_2010;362:1663_74.

71. Kedhi E, Joesoef KS, McFadden E, et al. Second-generation everolimus-eluting and paclitaxel-eluting stents in real-life practice (COMPARE): a randomised trial__Lancet 2010;375:201-9.

72. Rasmussen $\mathrm{K}_{2}$ Maeng $\mathrm{M}_{2}$ Kaltoft $\mathrm{A}_{2}$ et al; for SORT OUT III
Study Group. Efficacy and safety of zotarolimus-eluting and sirolimus-eluting coronary stents in routine clinical care (SORT OUT III): a randomised controlled superiority trial. Lancet_2010;375:1090_9.

73. Serruys PW, Silber S, Garg S, et al. Comparison of zotarolimus-eluting and everolimus-eluting coronary stents. $\mathrm{N} \mathrm{Engl}$ J Med 2010;363:136_46.

74. Jain AK, Lotan C, Meredith IT, et al; E-Five Registry Investigators. Twelve-month outcomes in patients with diabetes implanted with a zotarolimus-eluting stent: results from the E-Five Registry. Heart 2010;96:848-53.

75. Byrne RA, Kufner $\mathrm{S}_{2}$ Tiroch $\mathrm{K}_{2}$ et al; ISAR-TEST-3 Investigators. Randomised trial of three rapamycin-eluting stents with different coating strategies for the reduction of coronary restenosis: 2-year follow-up results._Heart_2009;95:1489_94.

76. Serruys $\mathrm{PW}_{2}$ Ormiston $\mathrm{JA}_{2}$ Onuma $\mathrm{Y}_{2}$ et al. A bioabsorbable everolimus-eluting coronary stent system (ABSORB): 2-year outcomes and results from multiple imaging methods. Lancet 2009;373:897_910.

77. Stone GW, Witzenbichler B, Guagliumi G, et al; on behalf of the HORIZONS-AMI Trial Investigators.Heparin plus a glycoprotein IIb/IIIa inhibitor versus bivalirudin monotherapy and paclitaxel-eluting stents versus bare-metal stents in acute myocardial infarction (HORIZONS-AMI): final 3-year results from a multicentre, randomised controlled trial_Lancet 2011;377:2193-204.

78. Spaulding $\mathrm{C}_{2}$ Rosencher $\mathrm{J}_{2}$ Varenne $\mathrm{O}_{-}$Use of drug eluting stents in ST segment elevation myocardial infarction. Heart 2010;96:1073-7.

79. Kaiser $\mathrm{C}_{2}$ Galatius $\mathrm{S}_{2}$ Erne $\mathrm{P}_{2}$ et al; for the BASKET-PROVE Study Group._Drug-eluting versus bare-metal stents in large coronary arteries. N Engl J Med_2010;363:2310-19.

80. Pfisterer $\mathrm{M}_{2}$ Brunner-La Rocca HP, Rickenbacher $\mathrm{P}_{2}$ et al. Long-term benefit-risk balance of drug-eluting vs. bare-metal stents in daily practice: does stent diameter matter? Three-year follow-up of BASKET.Eur Heart J_2009;30:16-24.

81. Cortese $\mathrm{B}_{2}$ Micheli $\mathrm{A}_{2}$ Picchi $\mathrm{A}_{2}$ et al_Paclitaxel-coated balloon versus drug-eluting stent during PCI of small coronary vessels, a prospective randomised clinical trial. The PICCOLETO study._Heart_2010;96:1291_6.

82. Unverdorben $\mathrm{M}$, Vallbracht $\mathrm{C}$, Cremers $\mathrm{B}$, et al. Paclitaxelcoated balloon catheter versus paclitaxel-coated stent for the treatment of coronary in-stent restenosis._Circulation 2009;119:2986-94.

83. Liistro $F_{2}$ Fineschi $M_{2}$ Grotti $S_{2}$ et al_LLong-term effectiveness and safety of sirolimus stent implantation for coronary in-stent restenosis: results of the TRUE (Tuscany Registry of sirolimus for unselected in-stent restenosis) registry at 4 years. J Am Coll Cardiol_2010;55:613_16.

84. Harjai KJ, Shenoy C, Orshaw P, et al. Dual antiplatelet therapy for more than 12 months after percutaneous coronary intervention: insights from the Guthrie PCI Registry. Heart 2009;95:1579_86.

85. Park SJ, Park DW, Kim $\mathrm{YH}_{2}$,et al__Duration of dual antiplatelet therapy after implantation of drug-eluting stents._. $\mathrm{N}$ Engl J Med_2010;362:1374-82.

86. Ho $\mathrm{PM}_{2}$ Tsai $\mathrm{TT}_{2}$ Maddox $\mathrm{TM}_{2}$ et al_.Delays in filling clopidogrel prescription after hospital discharge and adverse outcomes after drug-eluting stent implantation: Implications for transitions of care. Circ Cardiovasc Qual Outcomes_2010;3:261_6. 
87. Migliorini A, Valenti $\mathrm{R}_{2}$ Marcucci $\mathrm{R}_{2}$, et al_. High residual platelet reactivity after clopidogrel loading and long-term clinical outcome after drug-eluting stenting for unprotected left main coronary disease. Circulation_2009;120:2214-21.

88. Price MJ, Berger PB, Teirstein PS, et al; GRAVITAS Investigators_Standard- vs high-dose clopidogrel based on platelet function testing after percutaneous coronary intervention: the GRAVITAS randomized trial. JAMA 2011;305:1097-105.

89. Bonello $\mathrm{L}_{2}$ De Labriolle $\mathrm{A}_{2}$ Scheinowitz $\mathrm{M}_{2}$ et al_Emergence of the concept of platelet reactivity monitoring of response to thienopyridines. Heart 2009;95:1214-19.

90. Collet JP,Hulot JS, Pena A, et al. Cytochrome P450 2C19 polymorphism in young patients treated with clopidogrel after myocardial infarction: a cohort study. Lancet 2009;373:309-17.

91. Mega $\mathrm{JL}_{2}$ Close $\mathrm{SL}$, Wiviott $\mathrm{SD}_{2}$ et al.Cytochrome $\mathrm{p}-450$ polymorphisms and response to clopidogrel. $\mathrm{N}$ Engl J Med 2009;360:354-62.

92. Shuldiner $\mathrm{AR}_{2} \mathrm{O}$ 'Connell JR, Bliden $\mathrm{KP}_{2}$ et al._Association of cytochrome P450 2C19 genotype with the antiplatelet effect and clinical efficacy of clopidogrel therapy.JAMA 2009;302:849=57.

93. Paré G, Mehta SR, Yusuf S, et al. Effects of CYP2C19 genotype on outcomes of clopidogrel treatment. N Engl J Med 2010;363:1704_14.

94. Wallentin L, James S, Storey RF, et al; for the PLATO Investigators. Effect of CYP2C19 and ABCB1 single nucleotide polymorphisms on outcomes of treatment with ticagrelor versus clopidogrel for acute coronary syndromes: a genetic substudy of the PLATO trial_LLancet_2010;376:1320_8.

95. Würtz $\mathrm{M}_{2}$ Grove $\mathrm{EL}_{2}$ Kristensen $\mathrm{SD}_{2}$ et al. The antiplatelet effect of aspirin is reduced by proton pump inhibitors in patients with coronary artery disease. Heart 2010;96:368_71.

96. Charlot $\mathrm{M}_{2}$ Ahlehoff $\mathrm{O}_{2}$ Norgaard $\mathrm{ML}_{2}$ et al_.Proton-pump inhibitors are associated with increased cardiovascular risk independent of clopidogrel use: a nationwide cohort study. Ann Intern Med_2010;153:378_86.
97. Bhatt $\mathrm{DL}_{2}$ Cryer $\mathrm{BL}_{2}$ Contant $\mathrm{CF}_{2}$ et al; for the COGENT Investigators. Clopidogrel with or without omeprazole in coronary artery disease._N Engl J Med_2010;363:1909_17.

98. Scheiman JM, Devereaux PJ, Herlitz J_ et al_Prevention of peptic ulcers with esomeprazole in patients at risk of ulcer development treated with low-dose acetylsalicylic acid: a randomised, controlled trial (OBERON). Heart 2011;97:797-802.

99. Gremmel T, Steiner S, Seidinger D, et al. Calcium-channel blockers decrease clopidogrel-mediated platelet inhibition. Heart 2010;96:186-9.

100. Siller-Matula JM, Lang I, Christ G, et al. Calcium-channel blockers reduce the antiplatelet effect of clopidogrel. J Am Coll Cardiol_2008;52:1557-63.

101. Shroyer AL, Grover FL, Hattler B, et al; Veterans Affairs Randomized On/Off Bypass (ROOBY) Study Group._On-pump versus off-pump coronary-artery bypass surgery. N Engl J Med 2009;361:1827-37.

102. Kozora E, Kongs S, Collins JF, et al_. Cognitive outcomes after on- versus off-pump coronary artery bypass surgery. Ann Thorac Surg 2010;90:1134_41.

103. Møller $\mathrm{CH}_{2}$ Perko MJ_Lund JT, et al__No major differences in 30-day outcomes in high-risk patients randomized to off-pump versus on-pump coronary bypass surgery: the best bypass surgery trial.Circulation_2010;121:498_504.

104. Møller $\mathrm{CH}_{2}$ Perko MJ,Lund JT, et al. Three-year follow-up in a subset of high-risk patients randomly assigned to off-pump versus on-pump coronary artery bypass surgery: the Best Bypass Surgery Trial._Heart_2011;97:907_13.

105. Chukwuemeka A. Think "better bypass" before thinking “off-pump"?_Heart_2009;95:955_6.

106. Biancari $F_{2}$ Rimpiläinen R._Meta-analysis of randomised trials comparing the effectiveness of miniaturised versus conventional cardiopulmonary bypass in adult cardiac surgery. Heart_2009;95:964-9.

Corresponding author: Robert A Henderson, MD. Trent Cardiac centre. Nottingham University hospitals NHS Trust. Hucknall Road. Nottingham NG51PB, UK. E-mail: henderson@nuh.nhs.uk 